\title{
Insulin-dependent changes in subcellular distribution of liver insulin receptors in obese Zucker rats
}

\author{
S. López ${ }^{1}$, B. Desbuquois ${ }^{1}$, M.C. Postel-Vinay ${ }^{1}$, C. Benelli ${ }^{1}$ and M. Lavau ${ }^{2}$ \\ ${ }^{1}$ INSERM Unité 30, Hôpital des Enfants Malades, and \\ 2 INSERM Unité 177, Institut Biomédical des Cordeliers, Paris, France
}

\begin{abstract}
Summary. Acute hyperinsulinaemias induced by insulin and stimulants of insulin secretion have been shown to cause a translocation of liver insulin receptors from the cell surface to the intracellular compartment, with little or no change in total receptor number. To determine whether a similar phenomenon occurs in chronic hyperinsulinaemic states, we have carried out a longitudinal study of total, cell surface and intracellular liver insulin receptors in genetically obese Zucker rats, with spontaneously develop hyperinsulinaemia. Liver plasma membranes, Golgi-endosomal fractions, a microsomal fraction and a total particulate fraction were isolated in 2-14-week old obese ( $\mathrm{fa} / \mathrm{fa}$ ) rats and examined for specific insulin binding relative to lean $(\mathrm{Fa} /$ ?) age-matched animals. In 16-day old rats, which were still normoinsulinaemic, insulin binding was unchanged. Later on, as hyperinsulinaemia developed, three sequential changes in insulin
\end{abstract}

binding activity were observed: first, a $25-30 \%$ increase in Golgiendosomal fractions (20 days); then, a $50-60 \%$ decrease in Golgi-endosomal fractions ( $4-5$ weeks); and finally, a $50 \%$ decrease in plasma membranes ( 11 weeks), microsomal fraction and total particulate fraction (14 weeks), accompanied by restoration in Golgi-endosomal fractions ( 8 -11 weeks). Unlike insulin receptors, insulin extractable from Golgiendosomal fractions at 4-5 weeks was unchanged or increased. We conclude that, although an early increase in the endocytosis of liver insulin receptors may occur in hyperinsulinaemic Zucker rats, this mechanism does not account for the later decrease in cell surface receptors observed in these animals.

Key words: Insulin receptors, liver subcellular fractions, longlasting hyperinsulinaemia, obesity.
A decrease in the concentration of insulin receptors in cells has been observed in a number of rodent models in which plasma insulin concentration is chronically elevated, either spontaneously, such as genetic [1-14] and acquired [15] forms of obesity, or as a result of exogenous insulin administration $[16,17]$. This defect has been observed in liver [2-5, 8-13, 15], fat cells [7] and heart muscle membranes [1]; in hepatocytes [2, 12], adipocytes [16], and thymic lymphocytes $[4,5]$; and in isolated soleus muscle [10]. In most of these animal models, the insulin receptor defect is a function of the degree of the hyperinsulinaemia, suggesting that these two abnormalities are causally related.

The ability of insulin to decrease the concentration of its receptors in isolated cells is also well established [18]. Two basic mechanisms are known to be involved in this process: on the one hand, an increase in the rate of degradation of the receptors, and on the other hand, an increase in their rate of internalisation. Depending on the cell type, either enhanced receptor degradation $[19,20]$, or enhanced receptor internalisation [21], or both [22], have been reported. Much less is known, however, on the mechanism(s) underlying the insulin receptor defect found in chronic hyperinsulinaemic states.

Previous studies in this laboratory have shown that acute hyperinsulinaemias induced by insulin [23] and stimulants of insulin secretion [24] result in changes in the subcellular distribution of liver insulin receptors that suggest enhanced receptor internalisation. To determine whether similar changes occur in chronic hyperinsulinaemic states, we have carried out a longitudinal analysis of the subcellular distribution and the total number of hepatic insulin receptors in genetically obese Zucker rats.

\section{Materials and methods}

\section{Animals}

Sixteen to 30-day old obese Zucker rats ( $\mathrm{fa} / \mathrm{fa}$ ) and their lean littermates $(\mathrm{Fa} /$ ? ) were bred in the laboratory of Inserm U 177, Paris, France, from breeding pairs originally provided by the Harriet $\mathbf{G}$. 
Table 1. Specific characteristics of lean and obese Zucker rats at various ages

\begin{tabular}{|c|c|c|c|c|c|c|}
\hline \multirow[t]{2}{*}{ Age } & \multicolumn{2}{|c|}{ Body weight (g) } & \multicolumn{2}{|c|}{ Liver wet weight (g/rat) } & \multicolumn{2}{|c|}{ Plasma insulin concentration $(\mathrm{ng} / \mathrm{ml})$} \\
\hline & lean & obese & lean & obese & lean & obese \\
\hline 16 Days & $21.8 \pm 0.4$ & $23.3 \pm 0.5$ & $0.62 \pm 0.01$ & $0.64 \pm 0.01$ & $0.77 \pm 0.06$ & $0.95 \pm 0.12$ \\
\hline 23 Days & $38.3 \pm 0.9$ & $38.5 \pm 0.6$ & $1.54 \pm 0.05$ & $1.61 \pm 0.04$ & $0.93 \pm 0.18$ & $1.95 \pm 0.37^{\mathrm{a}}$ \\
\hline 4 Weeks & $53.7 \pm 1.5$ & $60.3 \pm 1.4^{b}$ & $2.34 \pm 0.08$ & $2.94 \pm 0.09^{\mathrm{a}}$ & $0.73 \pm 0.09$ & $2.12 \pm 0.21^{\mathrm{a}}$ \\
\hline 5 Weeks & $86.8 \pm 3.0$ & $112.0 \pm 2.1^{\mathrm{a}}$ & $4.50 \pm 0.24$ & $5.85 \pm 0.10^{\mathrm{a}}$ & $1.32 \pm 0.18$ & $6.36 \pm 0.80^{\mathrm{a}}$ \\
\hline 14 Weeks & $324.7 \pm 3.4$ & $447.0 \pm 6.3^{\mathrm{a}}$ & $11.60 \pm 0.20$ & $22.80 \pm 0.50^{\mathrm{a}}$ & $1.42 \pm 0.07$ & $20.92 \pm 2.49^{\mathrm{a}}$ \\
\hline
\end{tabular}

Animals described were used subsequently for liver subcellular fractionation and insulin binding assays. Values are mean \pm SEM of 4-33 determinations. ${ }^{\mathrm{a}} p<0.001$ vs control; ${ }^{\mathrm{b}} p<0.01$ vs control

Bird Memorial Laboratory (Stowe, Mass, USA). Pre-obese and lean pups were distinguished by plotting the weights of inguinal fat pads versus body weights, as previously described [25]. Five to 14-week old animals were purchased from the Centre de Sélection et d'Elevage d'Animaux de Laboratoire (Centre National de la Recherche Scientifique, Orléans, France). Their phenotype was identified by visual inspection and measurement of body weight. Sixteen to 23-day old rats were suckling; older animals were allowed free access to standard laboratory diet and water. Experiments were carried out so that obese and lean age-matched animals were studied at the same time. On the day scheduled for study, animals were weighed and killed by decapitation. Blood was collected for measurement of plasma insulin, and the liver was weighed and immediately homogenised.

\section{Subcellular fractionation}

Subcellular fractions were isolated from pools of 2-3 livers in 16-30day old rats and from separate livers in older animals. Routinely, 3-6 separate sets of subcellular fractions from both obese rats and their lean age-matched animals were prepared on the same day. A total particulate fraction, a plasma membrane fraction [26], a microsomal fraction and light, intermediate and heavy Golgi-endosomal fractions [27] were prepared as described previously. Originally isolated on the basis of a high content in the enzyme galactosyltransferase and on the presence of intraluminal lipoprotein particules, Golgi-endosomal fractions are now known to consist of two separate entities: true Golgi elements, which possess galactosyltransferase, and endosomes, which concentrate internalized ligands and presumably also their receptors. Subcellular fractions were stored in liquid nitrogen until used for biochemical determinations.

\section{Biochemical assays}

Insulin binding to liver subcellular fractions was measured ind the presence of Triton X-100 $(0.05 \%$, wt $/$ vol $)$ using ${ }^{125} \mathrm{I}$-insulin as a ligand and polyethyleneglycol precipitation as a method to separate free and receptor-bound insulin, as described previously [24]. Complete sets of subcellular fractions from livers of lean and obese rats of a given age were always assayed for insulin binding on the same day, and with the same batch of ${ }^{125}$ I-insulin. For each individual fraction, results (expressed in $\mathrm{cpm} / \mathrm{mg}$ protein) were the mean of triplicate determinations. Endogenous insulin associated with Golgiendosomal fractions was extracted by $0.1 \mathrm{~N} \mathrm{HCl}$ containing $1 \%$ $(\mathrm{w} / \mathrm{v})$ bovine serum albumin and $0.1 \%(\mathrm{w} / \mathrm{v})$ bacitracin $[24]$; recovery of insulin in the extract, as estimated from parallel experiments with Golgi-endosomal fractions loaded by ${ }^{125}$ I-insulin in vivo, was at least 90\% [23]. Insulin concentration in Golgi-endosomal extracts and blood plasma was measured by radioimmunoassay, using rat insulin as a standard [24]. Control experiments showed that the amount of endogenous insulin present in Golgi-endosomal fractions did not interfere with the insulin binding assay and, therefore, results did not require correction.

\section{Statistical analysis}

All statistical comparisons between obese $(\mathrm{fa} / \mathrm{fa})$ and lean $(\mathrm{Fa} /$ ?) rats of the same age were performed using the Student's $t$-test. For comparisons of insulin binding activities, values obtained in lean and obese rats were converted to percentages of the mean value observed in the lean animals of the same series. Because of the use of different batches of ${ }^{125} \mathrm{I}$-insulin to assay insulin binding in subcellular fractions from rat of different ages, no longitudinal comparisons were made within the lean or obese groups.

\section{Results}

\section{Body weight, liver weight and plasma insulin concentration}

Table 1 shows the developmental changes in body weight, liver weight and plasma insulin concentration in obese $(\mathrm{fa} / \mathrm{fa})$ and lean $(\mathrm{Fa} /$ ?) Zucker rats. The body weight and liver weight in obese rats did not differ from those in lean animals until 23 days, but became significantly greater $(p<0.01)$ after 4 weeks. Plasma insulin concentration in obese animals did not significantly differ from that in lean controls at 16 days, but progressively increased after 20 days (about 2, 5 and 10 -fold at 23 days, 5 weeks and 11 weeks respectively). Plasma insulin concentration in lean rats did not vary with age.

\section{Biochemical characterisation of liver subcellular fractions}

Average protein yields ( $\mu \mathrm{g}$ per g liver; mean \pm SEM of 3-7 determinations) in light, intermediate and heavy Golgi-endosomal fractions of 16-day old rats were, respectively, $99 \pm 4,147 \pm 8$ and $636 \pm 107$ in lean rats, and $87 \pm 6,138 \pm 8$ and $630 \pm 154$ in obese rats, with no 


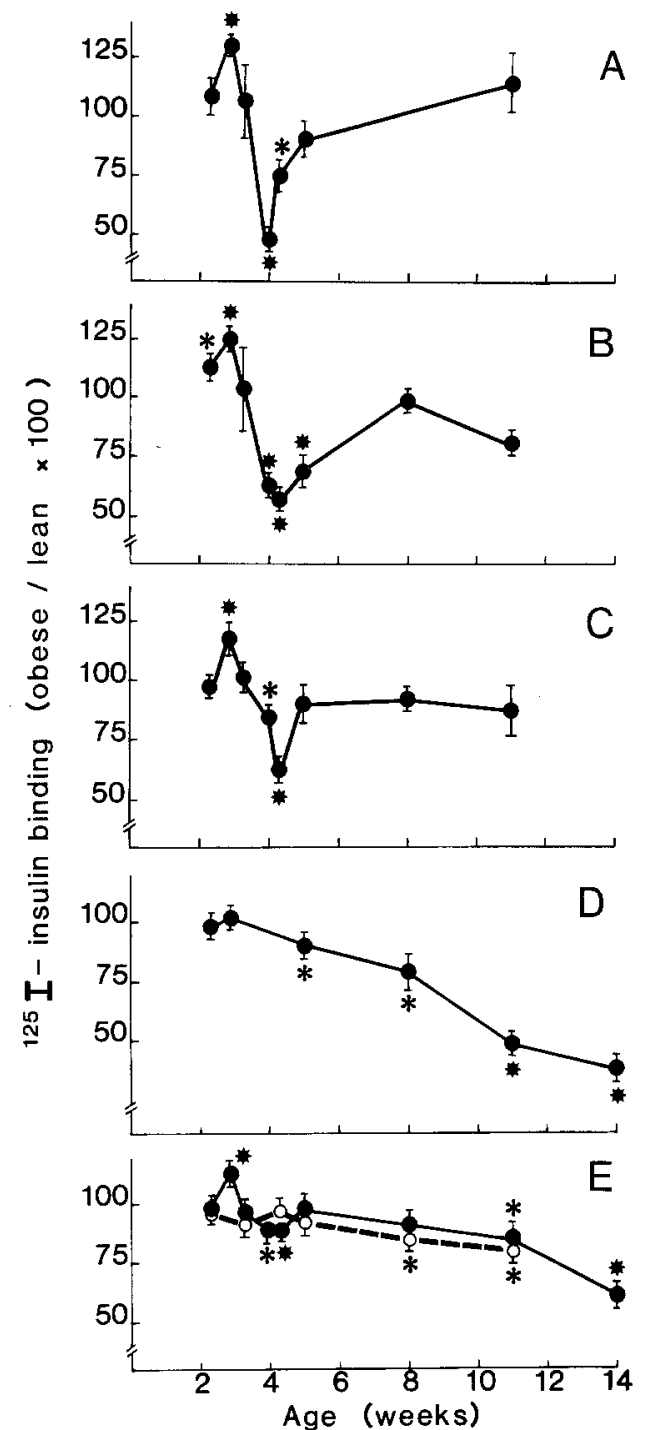

Fig. 1. Changes in specific insulin binding activity in light (panel A), intermediate (panel B) and heavy (panel C) Golgi-endosomal fractions, and in plasma membranes (panel D), microsomal fraction $(\bullet)$ and the total particulate fraction $(\mathrm{O})$ (panel E) as a function of age in obese Zucker rats. Results have been expressed as the percentage of the average insulin binding activity in lean rats ( $\mathrm{cpm} / \mathrm{mg}$ protein), as described in Materials and methods. The results shown are the mean \pm SEM of 4-16 determinations on separate subcellular fractions. The insulin binding activities in subcellular fractions from lean rats, expressed as femtomoles per mg protein (mean \pm SEM, 27-62 determinations) were 194 $\pm 19,310 \pm 10$, and $390 \pm 16$ for light, intermediate, and heavy Golgi-endosomal fractions and $634 \pm 32,133 \pm 10$, and $93 \pm 5$, for plasma membranes, microsomal fraction and total particulate fraction, respectively. ${ }^{*} p<0.001$ vs age-matched lean animals; ${ }^{*} p<0.05$ vs age-matched lean animals

significant difference between the two experimental groups. From 20 days to 11 weeks, protein yield decreased up to 2-fold in the light and intermediate Golgi-endosomal fractions of lean rats, and in the heavy Golgi-endosomal fraction of both lean and obese rats. Average protein yields in the microsomal and plasma membrane fractions were as described ear-

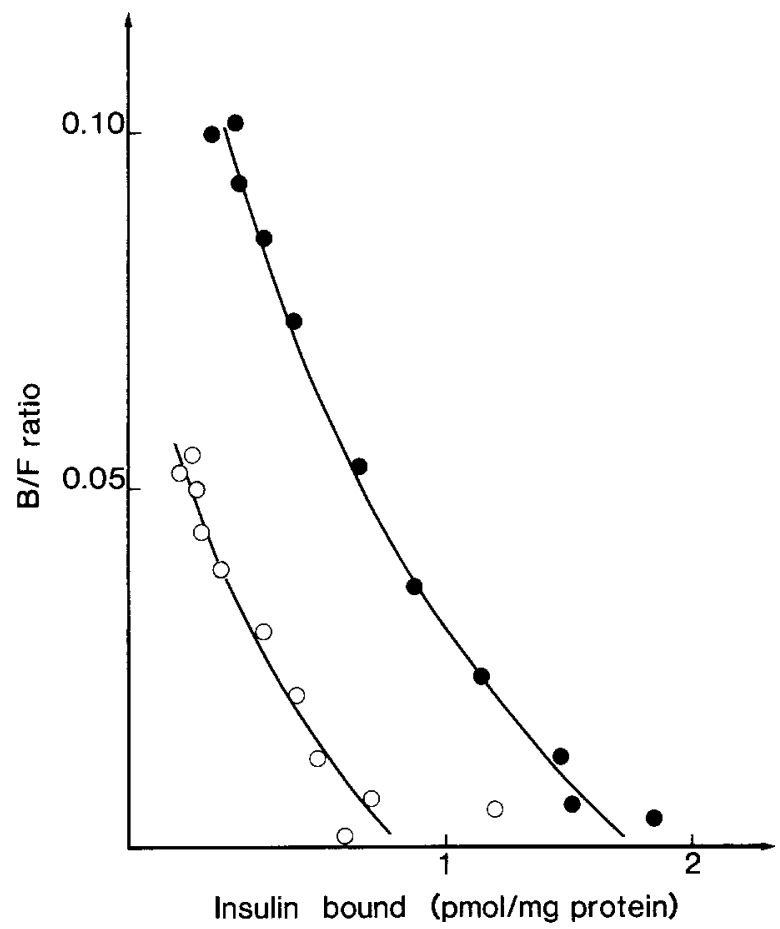

Fig. 2. Scatchard plots of specific insulin binding to the intermediate Golgi-endosomal fractions obtained from 30-day old obese $(O)$ and lean $(\bullet)$ Zucker rats. Golgi-endosomal fractions prepared from 15-18 livers were pooled within each experimental group. Scatchard plots were constructed from curves describing the inhibition of binding of labelled insulin $(0.2 \mathrm{nmol} / 1)$ to Golgi-endosomal fractions by increasing concentrations of native insulin $(0.03$ to $30 \mathrm{nmol} / 1)$. The shapes of the curves were comparable with the light and heavy Golgi-endosomal fractions (data not shown). B/F, bound to free ratio

lier in adult Sprague-Dawley rats [23], with no difference between lean and obese rats of the same age.

Specific activities of galactosyltransferase (a Golgi marker) in Golgi-endosomal fractions and 5'nucleotidase (a plasma membrane marker) in plasma membranes of Zucker rats were similar to those previously observed in adult Sprague-Dawley rats [24, 28] and did not differ in lean and obese rats of the same age (data not shown).

\section{Insulin binding to subcellular fractions}

In lean Zucker rats, the insulin binding activity of liver subcellular fractions was similar to that previously found in Sprague-Dawley rats [23, 24, 28], with a marked enrichment of binding activity in plasma membranes and in Golgi-endosomal fractions (about 7 fold and 2-4 fold, respectively; legend to Fig.1). In general, the subcellular distribution of binding sites was little affected by age, except for a somewhat greater enrichment in the light Golgi-endosomal fraction of 16-23-day old rats.

In 16-day old obese rats, which were still normoinsulinaemic (Table 1), insulin binding to liver subcel- 
Table 2. Concentration of immunoreactive insulin in acid extracts of intermediate and heavy Golgi-endosomal (GE) fractions from obese and lean Zucker rats of different ages

\begin{tabular}{|c|c|c|c|c|}
\hline \multirow{3}{*}{ Age } & \multicolumn{4}{|c|}{ Immunoreactive insulin (ng/mg protein) } \\
\hline & \multicolumn{2}{|c|}{ Intermediate GE fraction } & \multicolumn{2}{|c|}{ Heavy GE fraction } \\
\hline & lean & obese & lean & obese \\
\hline
\end{tabular}

The techniques used to extract and assay insulin from Golgi-endosomal fractions are described in Materials and methods. The results are the mean \pm SEM of 3-6 determinations on separate fractions. ${ }^{a} p<0.05$ vs control

lular fractions did not differ significantly from that observed in lean littermates. From 20 days on, however, as the hyperinsulinaemia developed, changes in insulin binding to subcellular fractions progressively occurred. Such changes affected first Golgi-endosomal fractions, then plasma membranes and finally the total particulate and microsomal fractions (Fig. 1).

Insulin binding to Golgi-endosomal fractions of obese rats showed somewhat complex changes, first increasing by $20-30 \%$ at 20 days, then decreasing by $40-60 \%$ at $4-5$ weeks, and finally increasing again towards control values after 8 weeks. The initial increase in insulin binding observed in 20-day old rats affected identically the three Golgi-endosomal fractions (Fig. 1, panels A, B, C), but the subsequent decrease in binding was somewhat greater in the light fraction, and so was the late increase in binding. Scatchard plots constructed from competitive inhibition curves by unlabelled insulin showed that the decreased ability of Golgi-endosomal fractions to bind insulin observed in 30 -day old obese rats resulted from a decrease in binding capacity, with little or no change in affinity (Fig. 2).

Insulin binding to other subcellular fractions was virtually unaffected until the age of 4 weeks (Fig. 1, panels D, E). Insulin binding to plasma membranes progressively decreased after 5 weeks, reaching about $80 \%$ of control values at 8 weeks and 50\% at 11 weeks. Insulin binding to the total particulate and microsomal fractions decreased more slowly and to a lesser extent, reaching about $80 \%$ and $60 \%$ of control values at 11 and 14 weeks respectively.

In the experiments described above, insulin binding activities in liver subcellular fractions were related to protein. Although protein yields of Golgi-endosomal fractions after 20 days somewhat differed in lean and obese rats, relative changes in insulin binding in obese rats were comparable when results were related to liver weight. However, due to an increase in liver weight in obese rats after 5 weeks, total receptor number was unchanged when related to the whole organ.

\section{Insulin content of Golgi-endosomal fractions}

When related to protein, the insulin content of the heavy Golgi-endosomal fraction was increased by 3-fold in 30-day old rats relatively to lean animals, but not such a change was observed in the intermediate Golgi-endosomal fraction of 30-day old rats, and in Golgi-endosomal fractions of 8 and 11-week old rats (Table 2). When related to liver weight, insulin content in the intermediate Golgi-endosomal fraction of 8 and 11 week-old obese animals was also increased. Thus, the decrease in insulin receptor number occurring in the intermediate and heavy Golgi-endosomal fractions of 30-day old rats was not accompanied by a parallel decrease in extractable insulin content, as would be expected if receptor endocytosis were diminished [28].

\section{Discussion}

A number of studies, utilising isolated liver subcellular fractions $[9,11,13,14,29]$, isolated hepatocytes $[12,30]$ and whole liver $[12,31]$ have examined the ability of insulin to bind to its receptors in genetically obese Zucker rats. Although a reduced number of hepatic receptors, when related to membrane protein, cell number or tissue weight, has been consistently observed in animals aged more than 4 months $[9,11,14]$, results obtained in 9-12-week old animals have been contradictory $[10,13,14,29,30]$. In addition, no studies have been performed in younger animals, in spite of the fact that hyperinsulinaemia already occurs at 3 weeks of age $[32,33]$, nor have the insulin receptors in the Golgiendosomal compartment been examined.

The present studies confirm that the decrease in the number of insulin receptors in liver plasma membranes of genetically obese Zucker rats is age-related, although occurring earlier ( 8 weeks) than found by other authors [9]. Furthermore, they show that the changes in insulin binding affect not only plasma membranes but also the Golgi-endosomal fractions, each fraction being affected in a specific manner and with a specific temporal sequence. In 16-day old rats, no changes in insulin binding were detectable. At 20 days, as plasma insulin concentration began to rise, the only change detectable was a $25-30 \%$ increase in insulin binding activity in Golgi-endosomal fractions. From 3 to 5 weeks, binding activity decreased by $50-60 \%$ in Golgi-endosomal fractions; concomittantly, insulin extractable from the latter increased by 3 -fold. 
After 5 weeks, binding activity decreased by $50 \%$ in plasma membranes and in the total particulate fraction, while being partially restored in Golgi-endosomal fractions.

After 3 weeks of age, the changes affecting insulin binding activity in obese Zucker rats clearly differed from those observed in rats rendered acutely hyperinsulinaemic by insulin [23] and stimulants of insulin secretion [24]. Indeed, in these acute hyperinsulinaemic states, the decrease in the number of cell-surface insulin receptors was associated with an increase in the number of intracellular receptors, and total receptor number was unaffected [23, 24]. In addition, although both 8-11-week old Zucker rats (present study) and glucose injected rats [24] displayed the same degree of hyperinsulinaemia, only in the latter was the insulin content of Golgi-endosomal fractions increased. On the other hand, the changes observed in Zucker rats more closely resemble those described in genetically obese ob/ob [2,3] and $\mathrm{db} / \mathrm{db}[3]$ mice. In these models, receptor number was decreased in plasma membranes, in the intermediate Golgi-endosomal fraction and in whole homogenates [2], especially the former. However, unlike in Zucker rats, insulin binding activity in the heavy Golgi-endosomal fraction of obese mice was either unaffected $(\mathrm{ob} / \mathrm{ob}$ model) or slightly increased ( $\mathrm{db} / \mathrm{db}$ model) [3]. Differences in the stage of the hyperinsulinaemia at which these models were studied might explain these discrepancies.

Based on the changes in the subcellular distribution of the receptors, we have earlier suggested that, in acute hyperinsulinaemic states, increased receptor internalisation is the major mechanism by which insulin regulates the concentration of its receptors at the surface of liver cells [23, 24]. That an increase in receptor internalisation also occurs in genetically obese hyperinsulinaemic Zucker rats, at least at an early stage, is suggested by the increase in insulin binding activity and insulin content in Golgi-endosomal fractions which occurs at 20 and 30 days respectively. A similar mechanism may also explain the increased number of insulin receptors in the heavy Golgi-endosomal fraction of $\mathrm{db} / \mathrm{db}$ mice reported previously [3]. However, the decrease in total cellular receptor number which occurs in both hyperinsulinaemic rodent models suggests that, at least at a late stage, an enhanced receptor degradation and/or a reduced receptor synthesis is/are the major mechanism(s) involved.

Recent studies using the diaminobenzidine density shift technique [34] have shown that liver Golgi-endosomal fractions as prepared in this work can be resolved in Golgi and endosomal components. Although insulin internalised into crude Golgi-endosomal fractions has been shown to associate exclusively with endosomes [35], it is unknown whether the internalised receptors also associates with this structure. Quantification of the receptors in physically resolved Golgi and endosomal components should help to elucidate the mechanisms by which acute $[23,24]$ and chronic hyperinsulinaemias regulate receptor number and distribution in liver cells.

Acknowledgments. We thank Mrs. H. Burlet, Mrs. A. Dupuis, and Mrs. C. Kayser for their excellent technical assistance. This work was supported by the Institut National de la Santé et de la Recherche Médicale and the Fondation de Recherche en Hormonologie, France.

\section{References}

1. Forgue ME, Freychet $P$ (1975) Insulin receptors in the heart muscle. Demonstration of specific binding sites and impairment of insulin binding in the plasma membrane of the obese hyperglycemic mouse. Diabetes 24: 715-723

2. Kahn CR, Neville DM, Roth J (1973) Insulin-receptor interaction in the obese-hyperglycemic mouse. A model of insulin resistance. J Biol Chem 248: 244-250

3. Posner BI, Raquidan D, Josefsberg Z, Bergeron JJM (1978) Different regulation of insulin receptors in intracellular (Golgi) and plasma membranes from livers of obese and lean mice. Proc Natl Acad Sci USA 75: 3302-3306

4. Soll AH, Goldfine ID, Roth J, Kahn CR (1974) Thymic lymphocytes in obese (ob/ob) mice. A mirror of the insulin receptor defect in liver and fat. J Biol Chem 249: 4127-4131

5. Soll AH, Kahn CR (1975) Insulin binding to liver plasma membranes in the obese hyperglycemic (ob/ob) mouse. J Biol Chem 250: 4702-4707

6. Soll AH, Kahn CR, Neville DM, Roth J (1975) Insulin receptor deficiency in genetic and acquired obesity. J Clin Invest 56: 769-780

7. Freychet $P$, Laudat $M H$, Laudat $P$, Rosselin $G$, Kahn CR, Gorden P, Roth J (1972) Impairment of insulin binding to fat cell plasma membrane in the obese hyperglycemic mouse. FEBS Lett $25: 339-342$

8. Kern P, Picard J, Caron M, Veissière D (1975) Decreased binding of insulin to liver plasma membrane receptors in hereditary diabetic mice. Biochim Biophys Acta 389: 281-289

9. Clark JB, Clark CM (1982) Age-related changes in insulin receptor regulation in liver membranes from Zucker fatty rats. Endocrinology 111: 964--969

10. Crettaz M, Prentki M, Zaninetti D, Jeanrenaud B (1980) Insulin resistance in soleus muscle from obese Zucker rats. Involvement of several defective sites. Biochem J 186: 525-534

11. Figlewicz DP, Dorsa DM, Stein LJ, Baskin DG, Paquette T, Greenwood MRC, Woods SC, Porte D (1985) Brain and liver insulin binding is decreased in Zucker rats carrying the "fa" gene. Endocrinology 117: 1537-1543

12. Karakash C, Jeanrenaud B (1983) Insulin binding and removal by livers of genetically obese rats. Diabetes 32: 605-609

13. Mahmood HA, Wood PJ, Marks V (1978) The effect of induced hyperglucagonaemia on the Zucker fatty rat. Diabetologia 14: 405-412

14. Steele NC, Martin RJ, Baile CA (1979) Insulin receptor characteristics and insulin degradation by Zucker lean and obese rats. Horm Metab Res 11: 525-526

15. Le Marchand Y, Freychet P, Jeanrenaud B (1978) Longitudinal study on the stablishment of insulin resistance in hypothalamic obese mice. Endocrinology 102: 74-85

16. Kobayashi M, Olefsky JM (1978) Effect of experimental hyperinsulinaemia on insulin binding and glucose transport in isolated rat adipocytes. Am J Physiol 235: E53-E62

17. Vigneri R, Pliam NB, Cohen DC, Pezzino V, Wong KY, Goldfine ID (1978) In vivo regulation of cell surface and intracellular insulin binding sites by insulin. J Biol Chem 253: 8192-8197 
18. Gavin JR, Roth J, Neville DM, De Meyts P, Buell DN (1974) Insulin-dependent regulation of insulin receptor concentration: a direct demonstration in cell culture. Proc Natl Acad Sci USA 71: $84-88$

19. Kasuga M, Kahn CR, Hedo JA, Van Obberghen E, Yamada KM (1981) Insulin-induced receptor loss in cultured human lymphocytes is due to accelerated receptor degradation. Proc Natl Acad Sci USA 78: 6917-6921

20. Ronnet GV, Knutson VP, Lane MD (1982) Insulin-induced down regulation of insulin receptors in 3T3-L1 adipocytes. Altered rate of receptor inactivation. J Biol Chem 257: 4285-4291

21. Krupp M, Lane MD (1981) On the mechanism of ligand-induced down-regulation of insulin receptor level in the liver cell. J Biol Chem 256: 1689-1694

22. Knutson VP, Ronnet GV, Lane MD (1983) Rapid, reversible internalization of cell surface insulin receptors. Correlation with insulin-induced down-regulation. J Biol Chem 258: 12139-12142

23. Desbuquois B, López S, Burlet H (1982) Ligand-induced translocation of insulin receptors in intact rat liver. J Biol Chem 257: 10852-10860

24. López S, Desbuquois B (1983) Changes in the subcellular distribution of insulin receptors in rat liver induced by acute endogenous hyperinsulinemia. Endocrinology 113: 783-789

25. Lavau M, Bazin R (1982) Inguinal fat pad weight plotted versus body weight as a method of genotype identification in 16-dayold Zucker rats. J Lipid Res 23: 941-943

26. Neville DM (1968) Isolation of an organ specific protein antigen from cell surface membrane of rat liver. Biochim Biophys Acta 154: $540-552$

27. Ehrenreich JH，Bergeron JJM， Siekevitz P，Palade GE (1973) Golgi fractions prepared from rat liver homogenates. I. Isolation procedure and morphological characterization. J Cell Biol 59: 45-72

28. López S, Desbuquois B (1987) Insulin-related changes in the subcellular distribution of insulin receptors in intact rat liver: effects of acute hypoinsulinemia induced by diazoxide, somatostatin, and xylazine. Endocrinology 120: 1695-1702
29. Clark JB, Stacey K, Clark CM (1982) Studies on the regulation of insulin binding by liver plasma membranes from Zucker fatty rats. Diabetes 31: 867-873

30. Broer Y, Freychet P, Rosselin G (1977) Insulin and glucagon-receptor interactions in the genetically obese Zucker rat: studies of hormone binding and glucagon-stimulated cyclic AMP levels in isolated hepatocytes. Endocrinology 101: 236-249

31. Sodoyez JC, Sodoyez-Goffaux F, Treves $S$, Kahn CR, von Frenckell $R$ (1984) In vivo imaging and quantitative analysis of insulin-receptor interaction in lean and obese Zucker rats. Diabetologia 26: 229-233

32. Bazin R, Lavau M (1982) Development of hepatic and adipose tissue lipogenic enzymes and insulinemia during suckling and weaning on to a high-fat diet in Zucker rats. J Lipid Res 23: 839-849

33. Zucker LM, Antoniades HN (1972) Insulin and obesity in the genetically obese rat "Fatty". Endocrinology 90: 1320-1330

34. Quintart J, Courtoy PJ, Baudhuin P (1984) Receptor-mediated endocytosis in rat liver: purification and enzymic characterization of low density organelles involved in uptake of galactose-exposing proteins. J Cell Biol 98: 877-884

35. Kay DG, Khan MN, Posner BI, Bergeron JJM (1984) In vivo uptake of insulin into hepatic Golgi fractions: application of the diaminobenzidine-shift protocol. Biochem Biophys Res Commun 123: $1144-1148$

Received: 26 April 1988

and in revised form: 7 October 1988

Dr. S. Lopez

INSERM U.30

Hôpital des Enfants Malades

149 , rue de Sèvres

F-75015 Paris

France 